\title{
A Comparative Study of the Interpretations of Emojis in Between U.S. and Chinese Users
}

\author{
Sherman Chui \\ School of English for International Business, Guangdong University of Foreign Studies, Guangzhou, China \\ Email address: \\ 201330003@oamail.gdufs.edu.cn
}

\section{To cite this article:}

Sherman Chui. A Comparative Study of the Interpretations of Emojis in Between U.S. and Chinese Users. International Journal of Literature and Arts. Special Issue: Humanity and Science: China's Intercultural Communication with the Outside World in the New Era.

Vol. 8, No. 3, 2020, pp. 108-118. doi: 10.11648/j.ijla.20200803.12

Received: February 27, 2020; Accepted: March 12, 2020; Published: April 8, 2020

\begin{abstract}
In recent years, Emojis have permeated online communications. They constantly show up in text messages, chats and emails, playing a significant role in business and daily interaction. Although designed to replace language text and to convert some universal emotions through icons, there are no rules governing people how to correctly define the sentiments behind them. Therefore, users with different cultural background may interpret emojis differently. This have often led to misinterpretation and miscommunication from different user groups. This study examines the correlation of the sentiments felt from a group of U.S. users versus a group of Chinese users by having them rate their sentiments from positive to negative for the top 15 most popularly used emojis. The survey was circulated in U.S. and China respectively and received 402 responses. The study weighted the scores of both user groups and analyzed the reasons behind the misalignment, including the structure of the icon, the local culture background etc. It founded that of the 15 emojis tested, over $60 \%$ of them had major or minor interpretation differences between the U.S. users and the Chinese users, and only $40 \%$ were aligned. The final conclusion was that the sentiment that the user intended to send with an emoji may not be received to the degree that it was intended among U.S. and Chinese users.
\end{abstract}

Keywords: Emojis, Misinterpretation, Culture Difference

\section{Introduction}

Emojis first showed up on Japanese cellphones in 1997. The first emoji was created by Mr. Shigetaka Kurita working for NTT DoCoMo's i-mode mobile Internet platform in 1999. He was inspired by Chinese characters and symbols depicting weather conditions on weather reports. He set out to design a bunch of symbols which can replace a string of text that can also embody emotions. The word Emoji in Japanese stands for $\mathrm{e}=$ picture, moji $=$ character. In 2016, the word Emoji became officially in the Webster Dictionary.

In 2010, 625 emoji characters were adopted into Unicode which allowed them to be used in international communication worldwide. They have expanded to over 3,000 by 2019 that included flags, food, and characters representing different races.

Some emojis have been adopted to use in local culture to mean something completely different from its original design. For example, the eggplant emoji $\hat{t}$ has been used in the digital world to mean a male organ while the peach emoji has been used to describe a buttock. As a result, in July 2019, the eggplant emoji and the peach emoji were banned by Facebook and Instagram. In a recent interview, Instagram stated that "[Content] will only be removed from Facebook and Instagram if it contains a sexual emoji alongside an implicit or indirect ask for nude imagery, sex or sexual partners, or sex chat conversations".

\section{Related Research}

\subsection{Emoji in Businesses}

Emojis are getting more and more popular in our daily life. They constantly show up between people's communication in the virtual world, such as social media, e-mail, and text message [10]. Some brands like McDonald's took emojis into their advertising campaigns [3]. In the workplace situation, Darics (2012) suggested that people using emojis tend to clarify the message and in order to reach a successful cooperation [5]. 
Another study showed that people have over a 92\% usage rate of emojis in their online communication [9]. Communicating emotions was the purpose of their design [7] and positive emotions communicating emoji are most popularly used on the Internet today [17].

\subsection{Difference of Interpretation}

Although emojis were designed to facilitate communications independent of written language, studies have shown that different people may interpret emoji differently [4, 16, 21]. Miller found that there was only $25 \%$ agreement on the meaning of emoji in their cross-platform study [16].

A Chinese study carried out by Gibson [8] found that the emoji face covering hand related to the use of laughter in interaction in specific cultural context. Another example that people interpreting the same emoji differently is the goat emoji . In the U.S., this stands for Greatest of All Time and is widely considered as a great compliment. In China, this acronym is not well known and is confusing to most people and in some cases may even be misconstrued as an insult. Likewise, there are local meanings attached to some emojis that are used in China that are only known mainly to the local population. An example of this would be the monkey emoji s s which in Chinese sounds like the word 好 meaning OK while most of the westerners would not have known this.

\subsection{Emoji and Body Communication}

Emoji is an expression of our inner emotion [12]. Alshenqeeti wrote, "Emojis are filling the need for adding nonverbal cues in digital communication about the intent and emotion behind a message" [1].

According to Herring and Dainas' analysis of the corpus of Facebook comments, emoji fulfilled a wider variety of functions beside emotional reactions, such as modifying the tone, depicting an element mentioned verbally, riffing, embodying an action, or representing a narrative sequence [13].

\subsection{Emoji and the Effectiveness of Communication}

Several researchers have discussed the positive or negative effects that emojis may lead to. Some argued that emojis filter out nonverbal/visual cues and can cause less effective communication outcomes [21]. Some argued that the absence of such cues does not necessarily cause less effective communication. Instead, this may trigger uncertainty in reduction strategies to make the compensation [2].

Studies attempt to analyze the results in different cases. One study showed that college counselors who used emojis in e-mails to their clients were perceived as having a lower level of expertise than those who did not [11]. However, applying emojis in the conversation between seller and potential buyers had a higher chance to close the deals than those who did not [14].

Researchers tried to examine how emojis influence customer service satisfaction [15]. Based on their findings, if consumers evaluated warmth, friendliness in the interaction, the use of emojis helped to increase the satisfaction level. Meanwhile, in some cases where consumers evaluated competence, the use of emojis turned out to decrease the satisfaction level. Therefore, whether emojis lead to positive or negative outcome is related to the customer expectations.

\subsection{Culture-related Reasons}

Park [18] found that emojis were not limited to conveying specific emotions of jokes, but further indicated socio-cultural norms, which can vary depending on the users' identity. They also pointed out that cultural differences may affect how people interpret emojis, and further explained the fact that easterners and westerners prefer different style of emojis.

Eid and Diener once assessed the emojis users experience between easterners and westerners, and they found both universal and culture-specific types of emotional experience [6]. It is expected that we can find both similarity and certain cultural patterns in the usage of emojis.

Several researchers have studied the role of culture in emoji expressions and perceptions. According to Tsai [19], Americans valued excitement while Asians preferred calmness. The Emoji system also contains cultural symbols and thus represented different values. A study suggested that culture played a significant role in perceptions of affect [22].

\subsection{Variances Between Different Platforms}

Despite the Unicode standards, many major platforms have created their own variants of the emoji. This means that the Apple's emoji for "Tears of Joy" is slightly different than the Google's android platforms' "Tears of Joy". Similarly, Twitter's version of emoji is slightly different from WeChat's version.

\section{Survey}

\subsection{Background of the Survey}

An online survey was circulated on http//:google.doc and on WeChat in U.S. and China respectively. Besides asking for basic demographic questions of 1) gender, 2) age and 3) job status, each respondent was asked to rate on a scale of 1 to 5 whether the emoji that were shown them made them feel positive (5) or negative (1).

From the website www.emojitracker.com, the top 15 most popularly used emoji were selected for this study.

Table 1. The Top 15 Most Popular Emoji Used in Twitter.

\begin{tabular}{ll}
\hline Emoji & $\begin{array}{l}\text { Number of Usage (By } \\
\left.\text { November } \mathbf{2 7}^{\text {th }}, \mathbf{2 0 1 9}\right)\end{array}$ \\
\hline F) Face with Tears of Joy & $2,627,324,280$ \\
Red Heart & $1,265,252,805$ \\
Recycling Symbol & $965,295,100$ \\
Smiling Face with Heart-Eyes & $949,938,383$ \\
Loudly Crying Face & $796,486,645$ \\
Heart Suit & $737,425,097$ \\
$\ominus$ Smiling Face with Smiling Eyes & $624,583,809$ \\
\hline
\end{tabular}




\begin{tabular}{|c|c|}
\hline Emoji & $\begin{array}{l}\text { Number of Usage (By } \\
\text { November } 27^{\text {th }}, 2019 \text { ) }\end{array}$ \\
\hline$\checkmark$ Two Hearts & $488,214,287$ \\
\hline (6) Face Throwing a Kiss & $470,444,639$ \\
\hline (2) Weary Face & $424,150,799$ \\
\hline (-) Smiling Face $\square$ & $386,495,251$ \\
\hline$\odot$ Pensive Face & $374,184,511$ \\
\hline () Grinning Face with Smiling Eyes & $359,479,483$ \\
\hline OK Hand Sign & $357,007,417$ \\
\hline
\end{tabular}

\subsection{Participants}

A total of 46 people responded from the U.S. survey representing a range of 18-40-years old users. More women, $63 \%$, answered than men, $37 \%$. The age of the respondents was fairly even with $4 \%$ being under $18,22 \%$ between $18-22$, $24 \%$ between $23-30,26 \%$ between $31-40$, and $24 \%$ being over 40 years of age. $30 \%$ were students, $48 \%$ were office workers, and $22 \%$ responded "others".

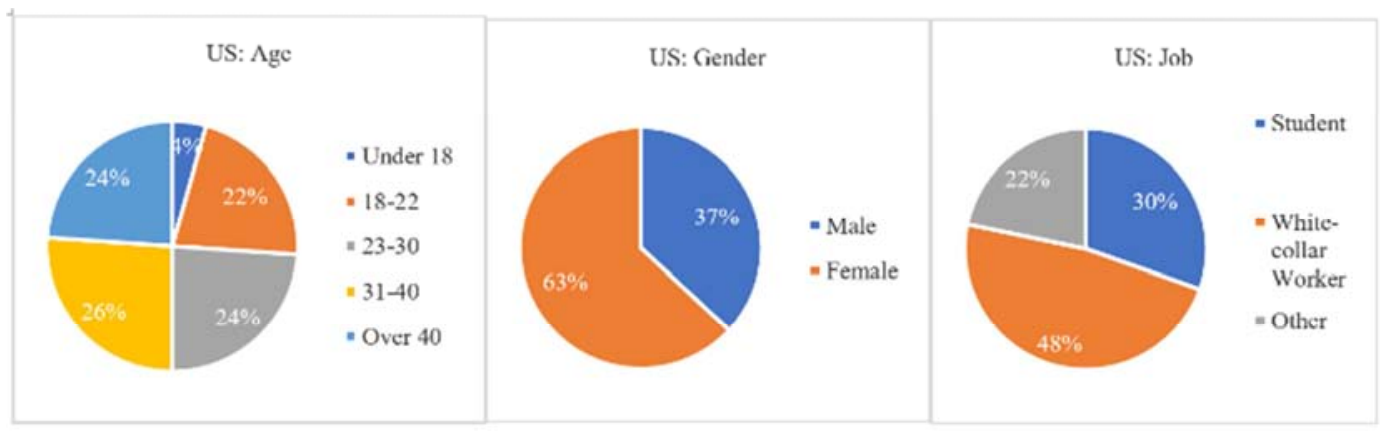

Figure 1. U.S. Participants' Background.

356 subjects also responded from the WeChat survey. 3\% of those who responded were under $18,77 \%$ were between $18-22$, $11 \%$ between $23-30,8 \%$ were between $31-40$, with only 2 of the 356 responders over 40 years old. $41 \%$ of the respondents were males, $59 \%$ females. The vast majority $(82 \%)$ were students with $12 \%$ workers and $6 \%$ others.

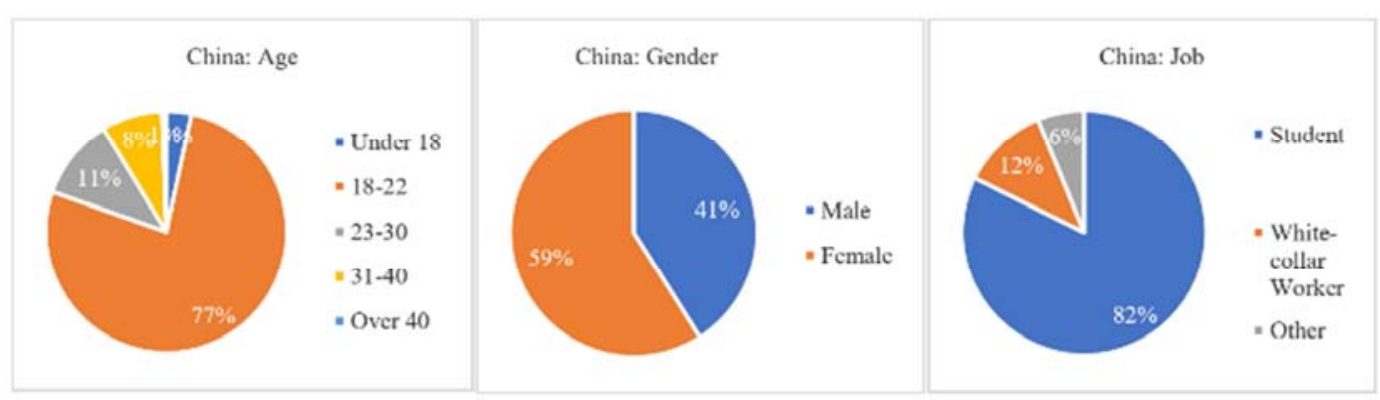

Figure 2. Chinese Participants' Background.

Table 2. Gender Distribution of the Participants.

\begin{tabular}{lll}
\hline Gender & China & U.S. \\
\hline Male & 17 & 146 \\
Female & 29 & 210 \\
Total & 46 & 356 \\
\hline
\end{tabular}

Table 3. Age Distribution of the Participants.

\begin{tabular}{lll}
\hline Age & China & U.S. \\
\hline Under 18 & 12 & 2 \\
$18-22$ & 274 & 10 \\
$23-30$ & 39 & 11 \\
$31-40$ & 29 & 12 \\
Over 40 & 2 & 11 \\
Total & 356 & 46 \\
\hline
\end{tabular}

Table 4. Job Distribution of the Participants.

\begin{tabular}{lll}
\hline Age & China & U.S. \\
\hline Student & 293 & 14 \\
White-collar Worker & 41 & 22 \\
Others & 22 & 10 \\
Total & 356 & 46 \\
\hline
\end{tabular}

\section{Analysis and the Results}

\subsection{Alignment}

\subsubsection{Smiling Face with Heart-Eyes}

This is a face with a pair of love-struck eyes. It conveys feelings of love and adoration for someone or something. It was approved within Unicode 6.0 and added to Emoji 1.0 in 2015. In this survey, the sentiment was agreed by both group of users. $96 \%$ of China respondents and $95.7 \%$ of U.S. respondents found it neutral to positive. The Chinese users had extremely favorable reaction to it with $61 \%$ of them rating it a 5 while $28.3 \%$ of U.S. respondents rating it the same. The strong reaction drove the average to a high score of 4.40 for the Chinese survey which was very close to the 3.91 average for the U.S. survey. The weighted average difference was 0.49 . Result: Alignment. 


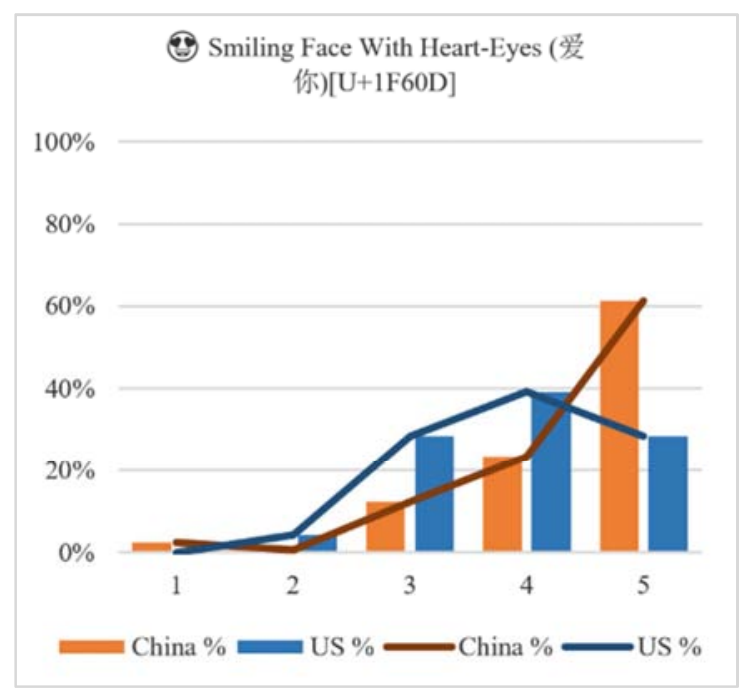

Figure 3. Histogram of the Emoji "Smiling Face with Heart-Eyes".

Table 5. Score Distribution of the Emoji "Smiling Face with Heart-Eyes".

\begin{tabular}{lllll}
\hline Score & $\begin{array}{l}\text { Number of } \\
\text { Response } \\
\text { (China) }\end{array}$ & $\begin{array}{l}\text { Percentage } \\
\text { of Response } \\
\text { (China) }\end{array}$ & $\begin{array}{l}\text { Number of } \\
\text { Response } \\
\text { (U.S.) }\end{array}$ & $\begin{array}{l}\text { Percentage } \\
\text { of Response } \\
\text { (U.S.) }\end{array}$ \\
\hline 1 & 9 & $3 \%$ & 0 & $0 \%$ \\
2 & 2 & $1 \%$ & 2 & $4.3 \%$ \\
3 & 44 & $12 \%$ & 13 & $28.3 \%$ \\
4 & 83 & $23 \%$ & 18 & $39.1 \%$ \\
5 & 218 & $61 \%$ & 13 & $28.3 \%$ \\
Total & 356 & & 46 & \\
\hline
\end{tabular}

\subsubsection{Unamused Face}

This emoji has eyes looking to the lower left of the face along with a frown and slightly raised eyebrows. This connotes irritation, displeasure and skepticism. It was approved as part of Unicode 6.0 in 2010 and added to Emoji 1.0 in 2015. Out of all the respondents from both countries, only 5 respondents found it strongly positive. $65.4 \%$ of China respondents and $91.3 \%$ of U.S. respondents rated it a 1 or 2 which making it a negative symbol. The weighted average of China respondents was 2.24 and U.S. was 1.89 . The D-value is 0.35. Result: Alignment.

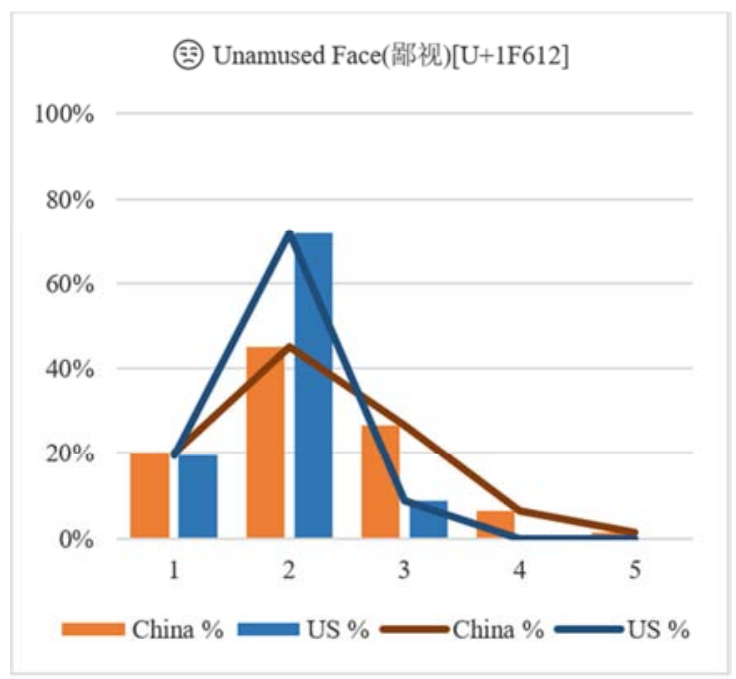

Figure 4. Histogram of the Emoji "Unamused Face".
Table 6. Score Distribution of the Emoji "Unamused Face”.

\begin{tabular}{lllll}
\hline Score & $\begin{array}{l}\text { Number of } \\
\text { Response } \\
\text { (China) }\end{array}$ & $\begin{array}{l}\text { Percentage } \\
\text { of Response } \\
\text { (China) }\end{array}$ & $\begin{array}{l}\text { Number of } \\
\text { Response } \\
\text { (U.S.) }\end{array}$ & $\begin{array}{l}\text { Percentage } \\
\text { of Response } \\
\text { (U.S.) }\end{array}$ \\
\hline 1 & 72 & $20.2 \%$ & 9 & $19.6 \%$ \\
2 & 161 & $45.2 \%$ & 33 & $71.7 \%$ \\
3 & 95 & $26.7 \%$ & 4 & $8.7 \%$ \\
4 & 23 & $6.5 \%$ & 0 & $0 \%$ \\
5 & 5 & $1.4 \%$ & 0 & $0 \%$ \\
Total & 356 & & 46 & \\
\hline
\end{tabular}

\subsubsection{Weary Face}

A yellow face with furrowed eyebrows and a wide-open frown. It shows frustration or sadness. However, this may be used as affection which shows tolerance to a negative situation. It was part of Unicode 6.0 and added to Emoji 1.0 in 2015. Both groups of respondents shared the similar understanding of this emoji. Of 356 China respondents, $83.9 \%$ of them rated it a 1 or 2 . Similarly, $80 \%$ of U.S. respondents rated it a 1 or 2 . Of the remaining respondents, $10.7 \%$ rated it neutral, $2.8 \%$ rated it a 4 , and $2.5 \%$ rated it a 5 . The weighted average of the two surveys were similar as China scored 1.72 and U.S. scored 2.02. The D-value was 0.30. Result: Alignment.

Table 7. Score Distribution of the Emoji "Weary Face".

\begin{tabular}{lllll}
\hline Score & $\begin{array}{l}\text { Number of } \\
\text { Response } \\
\text { (China) }\end{array}$ & $\begin{array}{l}\text { Percentage } \\
\text { of Response } \\
\text { (China) }\end{array}$ & $\begin{array}{l}\text { Number of } \\
\text { Response } \\
\text { (U.S.) }\end{array}$ & $\begin{array}{l}\text { Percentage } \\
\text { of Response } \\
\text { (U.S.) }\end{array}$ \\
\hline 1 & 186 & $52.2 \%$ & 8 & $17 \%$ \\
2 & 113 & $31.7 \%$ & 29 & $63 \%$ \\
3 & 38 & $10.7 \%$ & 9 & $20 \%$ \\
4 & 10 & $2.8 \%$ & 0 & $0 \%$ \\
5 & 9 & $2.5 \%$ & 0 & $0 \%$ \\
Total & 356 & & 46 & \\
\hline
\end{tabular}

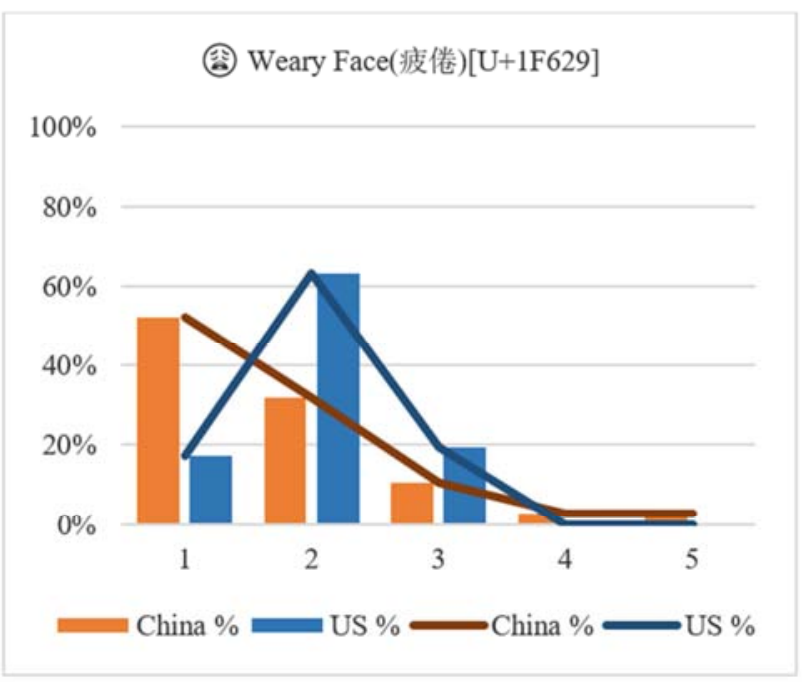

Figure 5. Histogram of the Emoji "Weary Face".

\subsubsection{OK Hand Sign}

A hand signal that shows the right index finger touching the right thumb in an open circle that in most societies convey the meaning of "OK" or correct. In parts of Europe, Middle East and South America, the same symbol can be considered offensive. In American Sign Language, this however 
represents the number nine. The $\mathrm{OK}$ hand was approved as part of Unicode 6.0 in 2010 under the name "OK Hand Sign" and added to Emoji 1.0 in 2015. In this survey, both China users and U.S. users had the same conclusion that this sign represented neutral feelings. $62.6 \%$ of China rated it a 3 out of 5 and similarly, $45.7 \%$ of U.S. users rated 3 . The weighted average of China was 3.46 and U.S. was 3.20. The D-value was 0.26 , making it the 3 rd closest alignment of the 15 emoji tested. Result: Alignment.

Table 8. Score Distribution of the Emoji "OK Hand Sign”.

\begin{tabular}{lllll}
\hline Score & $\begin{array}{l}\text { Number of } \\
\text { Response } \\
\text { (China) }\end{array}$ & $\begin{array}{l}\text { Percentage } \\
\text { of Response } \\
\text { (China) }\end{array}$ & $\begin{array}{l}\text { Number of } \\
\text { Response } \\
\text { (U.S.) }\end{array}$ & $\begin{array}{l}\text { Percentage } \\
\text { of Response } \\
\text { (U.S.) }\end{array}$ \\
\hline 1 & 4 & $1.1 \%$ & 0 & $0 \%$ \\
2 & 13 & $3.7 \%$ & 10 & $21.7 \%$ \\
3 & 223 & $62.6 \%$ & 21 & $45.7 \%$ \\
4 & 46 & $12.9 \%$ & 11 & $23.9 \%$ \\
5 & 70 & $19.7 \%$ & 4 & $8.7 \%$ \\
Total & 356 & & 46 & \\
\hline
\end{tabular}

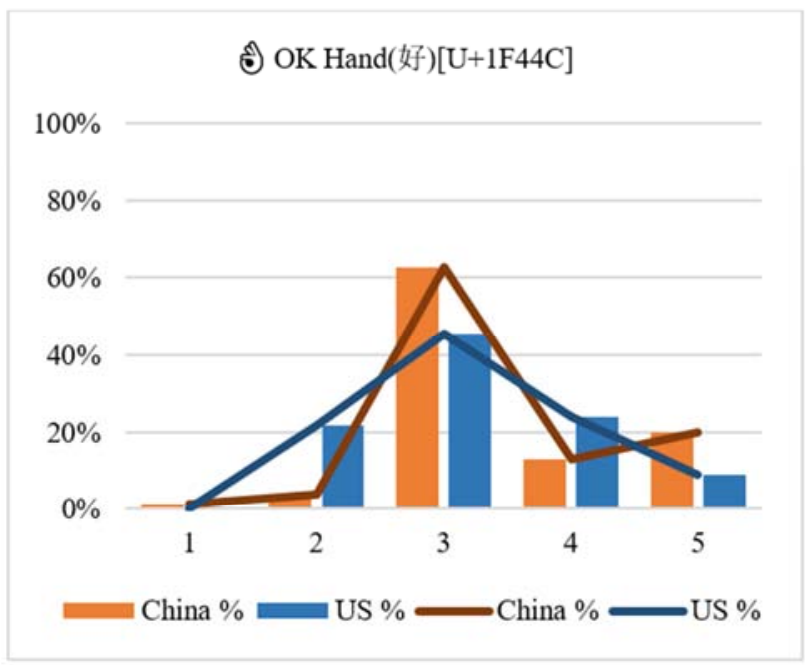

Figure 6. Histogram of the Emoji "OK Hand Sign".

\subsubsection{Pensive Face}

This is a face showing remorse and signs of disappointment. It is less strong than "Loudly Crying Face and indicates self-reflection. It is a sad face with closed eyes along with furrowed eyebrows. It is part of Unicode 6.0 in 2010 and was added to Emoji 1.0 in 2015. In the survey, a high percentage of both China and U.S. users rated it below $3.83 \%$ of China users considered it a negative or very negative emoji and $80.4 \%$ of U.S. users had the same conclusion. 13\% of China users and $17.4 \%$ of U.S. respondents rated it neutral. The weighted average of the two groups was very close: China scored 1.86; U.S. scored 2.07. The D-value (0.21) is the 2nd lowest among the 15 emoji. Result: Alignment.

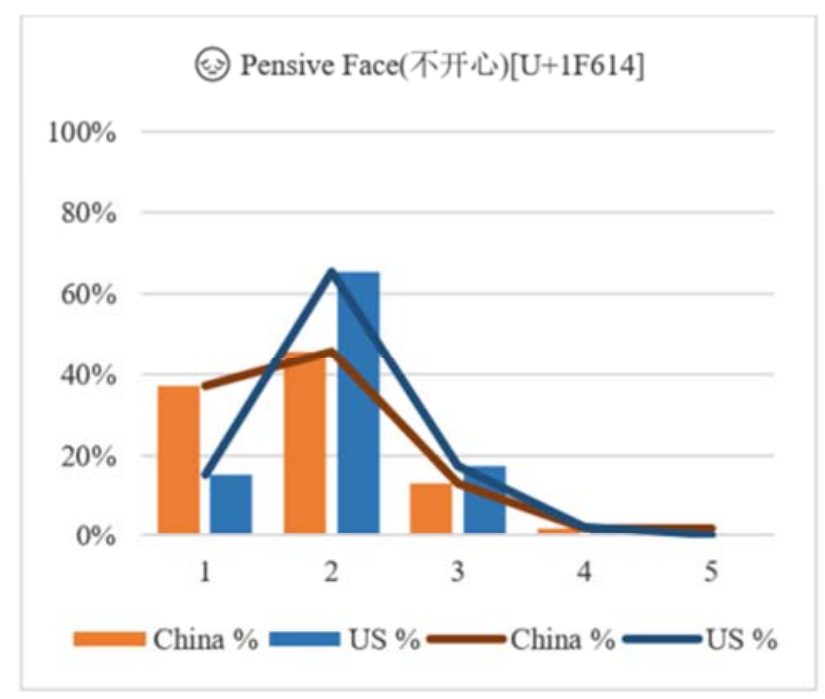

Figure 7. Histogram of the Emoji "Pensive Face".

Table 9. Score Distribution of the Emoji "Pensive Face".

\begin{tabular}{lllll}
\hline Score & $\begin{array}{l}\text { Number of } \\
\text { Response } \\
\text { (China) }\end{array}$ & $\begin{array}{l}\text { Percentage } \\
\text { of Response } \\
\text { (China) }\end{array}$ & $\begin{array}{l}\text { Number of } \\
\text { Response } \\
\text { (U.S.) }\end{array}$ & $\begin{array}{l}\text { Percentage } \\
\text { of Response } \\
\text { (U.S.) }\end{array}$ \\
\hline 1 & 132 & $37 \%$ & 7 & $15.2 \%$ \\
2 & 163 & $46 \%$ & 30 & $65.2 \%$ \\
3 & 47 & $13 \%$ & 8 & $17.4 \%$ \\
4 & 7 & $2 \%$ & 1 & $2.2 \%$ \\
5 & 7 & $2 \%$ & 0 & $0 \%$ \\
Total & 356 & & 46 & \\
\hline
\end{tabular}

\subsubsection{Loudly Crying Face}

This is one of the strongest emotionally invoking emoji among the Emoji 1.0 set. It shows an open mouth crying loudly with large streams of tears flowing down both cheeks versus smaller teardrops. On the flip side, netizens have sometimes used it in communications with known entities as uncontrollable laughter or overwhelming joy. The majority of China and U.S. respondents (China: 68.6\%; U.S.: 76.1\%) interpreted it as a very negative or mainly negative emoji. $24.4 \%$ of China respondents and $13 \%$ of U.S. respondents rated it neutral. Very few respondents from China and U.S. rated it positive. This highly similar interpretation led to the first agreement between the two groups. The weighted average of China was 2.08 which was very close with the 2.04 of U.S. The D-value was 0.04. Result: Alignment.

Table 10. Score Distribution of the Emoji "Loudly Crying Face".

\begin{tabular}{lllll}
\hline Score & $\begin{array}{l}\text { Number of } \\
\text { Response } \\
\text { (China) }\end{array}$ & $\begin{array}{l}\text { Percentage } \\
\text { of Response } \\
\text { (China) }\end{array}$ & $\begin{array}{l}\text { Number of } \\
\text { Response } \\
\text { (U.S.) }\end{array}$ & $\begin{array}{l}\text { Percentage } \\
\text { of Response } \\
\text { (U.S.) }\end{array}$ \\
\hline 1 & 121 & $34.0 \%$ & 16 & $34.8 \%$ \\
2 & 123 & $34.6 \%$ & 19 & $41.3 \%$ \\
3 & 87 & $24.4 \%$ & 6 & $13.0 \%$ \\
4 & 14 & $3.9 \%$ & 3 & $6.5 \%$ \\
5 & 11 & $3.1 \%$ & 2 & $4.3 \%$ \\
Total & 356 & & 46 & \\
\hline
\end{tabular}




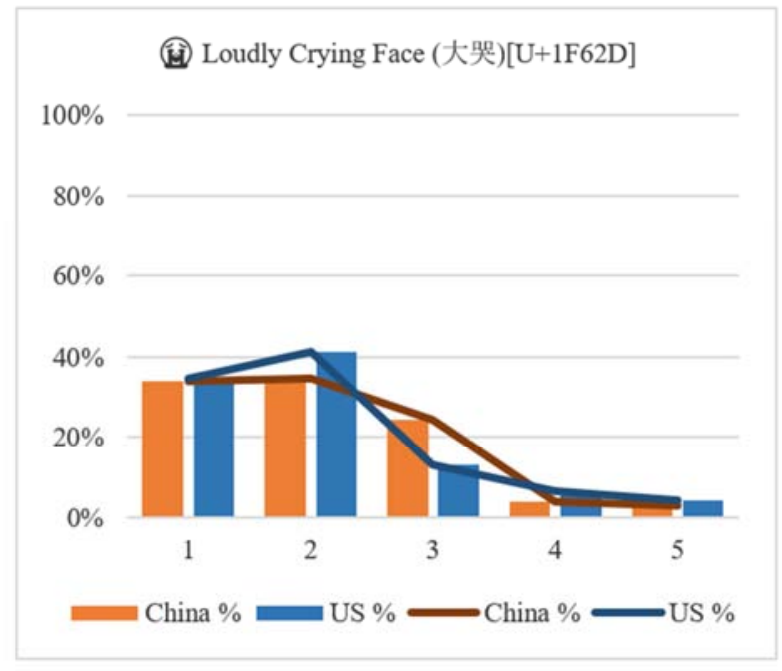

Figure 8. Histogram of the Emoji "Loudly Crying Face".

\subsection{Minor Misalignment}

\subsubsection{Smiling Face}

This is a more restricted smile that showcases a modest smile. It shows rosy cheeks and closed eyes. It generally is associated with love, happiness and gratitude. Approved as part of Unicode 1.1 in 1993. It was added to Emoji 1.0 in 2015. The data showed a major difference between China and U.S. users in the interpretation. A large group of China users $(41.3 \%)$ rated it a 4 out of 5 while a large group of U.S. users $(47.8 \%)$ rated it a 2 out of 5 . Both China and U.S. users did not think this emoji represent strong emotion. $22.8 \%$ of China users and $21.7 \%$ of U.S. users rated it a 3 . The weighted average showed a significant difference that China scored 3.79 while U.S. scored 2.85. The D-value was 0.94 . Result: Minor misalignment.

\section{(2): Smiling Face(微笑) $[\mathrm{U}+263 \mathrm{~A}]$}

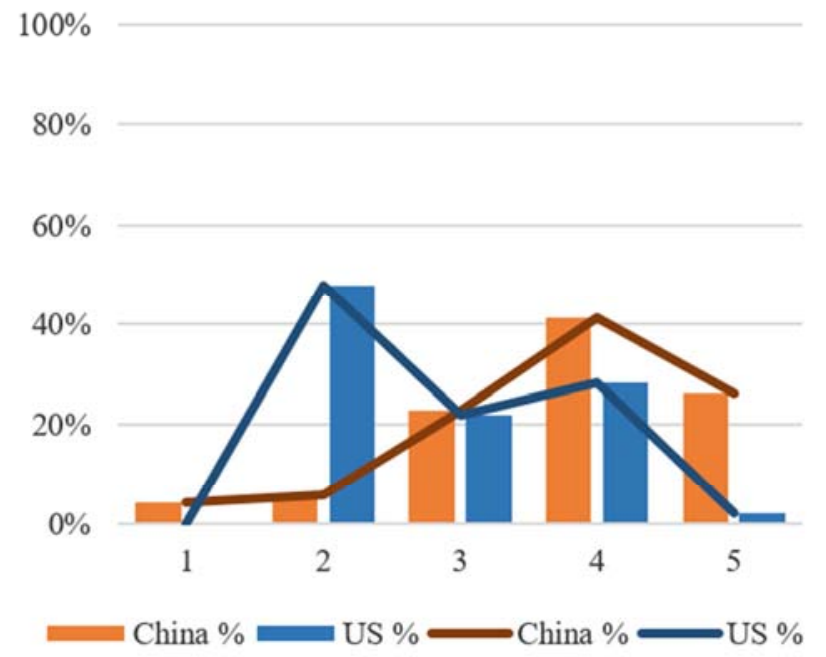

Figure 9. Histogram of the Emoji "Smiling Face”.
Table 11. Score Distribution of the Emoji "Smiling Face".

\begin{tabular}{lllll}
\hline Score & $\begin{array}{l}\text { Number of } \\
\text { Response } \\
\text { (China) }\end{array}$ & $\begin{array}{l}\text { Percentage } \\
\text { of Response } \\
\text { (China) }\end{array}$ & $\begin{array}{l}\text { Number of } \\
\text { Response } \\
\text { (U.S.) }\end{array}$ & $\begin{array}{l}\text { Percentage } \\
\text { of Response } \\
\text { (U.S.) }\end{array}$ \\
\hline 1 & 15 & $4.2 \%$ & 0 & $0 \%$ \\
2 & 20 & $5.6 \%$ & 22 & $47.8 \%$ \\
3 & 81 & $22.8 \%$ & 10 & $21.7 \%$ \\
4 & 147 & $41.3 \%$ & 13 & $28.3 \%$ \\
5 & 93 & $26.1 \%$ & 1 & $2.2 \%$ \\
Total & 356 & & 46 & \\
\hline
\end{tabular}

\subsubsection{Face with Tears of Joy}

This was the most popular emoji from 2014-2019 and was named the Oxford dictionary's Word of the Year of 2015. It was approved as part of Unicode 6.0 in 2010 and was added to Emoji 1.0 in 2015. The weighted average of the Chinese survey was 3.75 while the U.S. scored 2.89. The difference between the 2 average weighted score (D-value) was 0.86 . This was the $4^{\text {th }}$ highest difference within the 15 emojis tested and was the $2^{\text {nd }}$ highest among all face scores. This emoji caused much divergence despite it being the most heavily used of all the emojis in twitter from 2014 to 2019. This particular emoji has both tears (negative sentiments) and an open smile (positive sentiments) so presented users with a choice of interpreting it as sheer bliss or crying heavily. Both Chinese and US users had responses at both ends of the sentiments with U.S. rating it collectively $54.3 \%$ as either strongly or slightly negative while Chinese participants rated overall positive with $58.5 \%$ slightly or strongly positive. Result: Minor misalignment.

Table 12. Score Distribution of the Emoji "Face with Tears of Joy".

\begin{tabular}{lllll}
\hline Score & $\begin{array}{l}\text { Number of } \\
\text { Response } \\
\text { (China) }\end{array}$ & $\begin{array}{l}\text { Percentage } \\
\text { of Response } \\
\text { (China) }\end{array}$ & $\begin{array}{l}\text { Number of } \\
\text { Response } \\
\text { (U.S.) }\end{array}$ & $\begin{array}{l}\text { Percentage } \\
\text { of Response } \\
\text { (U.S.) }\end{array}$ \\
\hline 1 & 6 & $1.7 \%$ & 3 & $6.5 \%$ \\
2 & 31 & $8.7 \%$ & 22 & $47.8 \%$ \\
3 & 111 & $31.2 \%$ & 7 & $15.2 \%$ \\
4 & 106 & $29.8 \%$ & 5 & $10.9 \%$ \\
5 & 102 & $28.7 \%$ & 9 & $19.6 \%$ \\
Total & 356 & & 46 & \\
\hline
\end{tabular}

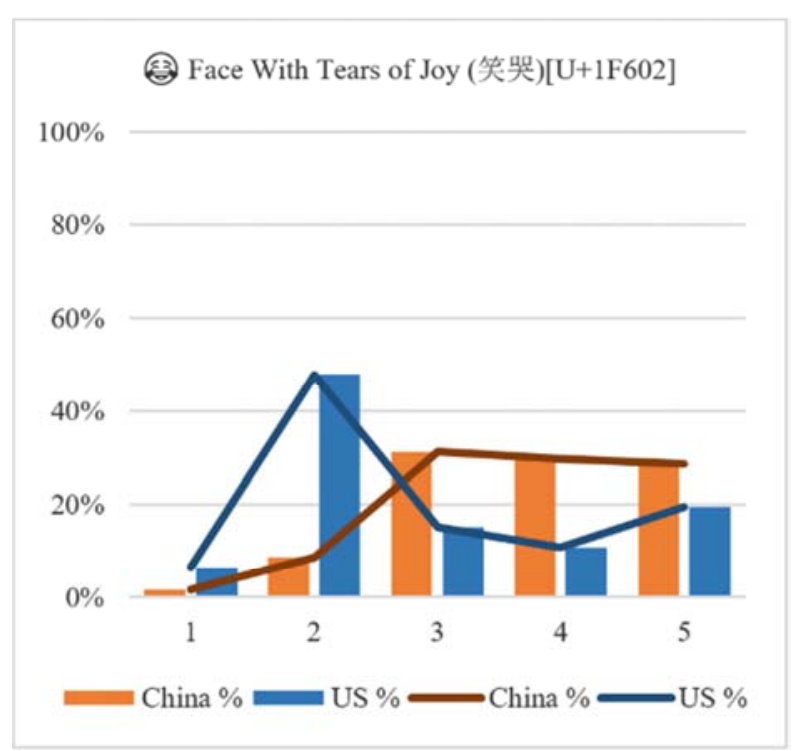

Figure 10. Histogram of the Emoji "Face with Tears of Joy". 


\subsubsection{Face Throwing a Kiss}

This shows a face winking and puckering to blow on a heart shape. This is used to send affection to someone who is about to leave or going to sleep. This is used among people who have achieved comfort with each other in a relationship. Face throwing a kiss was approved within Unicode 6.0 and added to Emoji 1.0 in 2015. The highest percentage of Chinese respondents $(68.5 \%)$ rated it a 5 of $5.39 .1 \%$ of U.S. respondents considered it as a mainly neutral emoji while $34.8 \%$ found it slightly positive and $19.6 \%$ found it strongly positive. The weighted average of China was 4.53 and U.S. was 3.67. The D-value was 0.86. Result: Minor misalignment.

Table 13. Score Distribution of the Emoji "Face Throwing a Kiss"

\begin{tabular}{lllll}
\hline Score & $\begin{array}{l}\text { Number of } \\
\text { Response } \\
\text { (China) }\end{array}$ & $\begin{array}{l}\text { Percentage } \\
\text { of Response } \\
\text { (China) }\end{array}$ & $\begin{array}{l}\text { Number of } \\
\text { Response } \\
\text { (U.S.) }\end{array}$ & $\begin{array}{l}\text { Percentage } \\
\text { of Response } \\
\text { (U.S.) }\end{array}$ \\
\hline 1 & 8 & $2.2 \%$ & 0 & $0 \%$ \\
2 & 3 & $0.8 \%$ & 3 & $6.5 \%$ \\
3 & 25 & $7.0 \%$ & 18 & $39.1 \%$ \\
4 & 76 & $21.3 \%$ & 16 & $34.8 \%$ \\
5 & 244 & $68.5 \%$ & 9 & $19.6 \%$ \\
Total & 356 & & 46 & \\
\hline
\end{tabular}

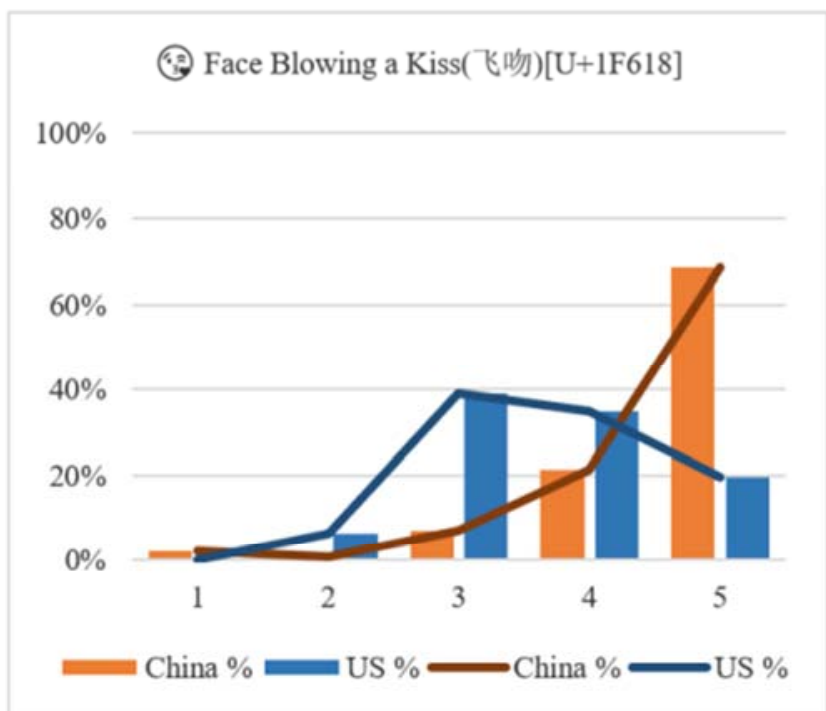

Figure 11. Histogram of the Emoji "Face Throwing a Kiss".

\subsubsection{Two Hearts}

Two pink hearts one smaller than the other gives the feeling that the front heart is connected to back heart that is further away. The pink color shows gentleness which brings up feelings of a slow romance. Both respondents from China and U.S. agreed that the emoji indicated positive feelings. $91 \%$ of China respondents agreed it as positive or very positive emoji while $51.7 \%$ of U.S. respondents thought the same. $41.3 \%$ of U.S. users thought the emoji showed a neutral feeling. The weighted average of China was 4.51 and U.S. was 3.65. The D-value was 0.86. Result: Minor misalignment.
Table 14. Score Distribution of the Emoji "Two Hearts".

\begin{tabular}{lllll}
\hline Score & $\begin{array}{l}\text { Number of } \\
\text { Response } \\
\text { (China) }\end{array}$ & $\begin{array}{l}\text { Percentage } \\
\text { of Response } \\
\text { (China) }\end{array}$ & $\begin{array}{l}\text { Number of } \\
\text { Response } \\
\text { (U.S.) }\end{array}$ & $\begin{array}{l}\text { Percentage } \\
\text { of Response } \\
\text { (U.S.) }\end{array}$ \\
\hline 1 & 5 & $1.4 \%$ & 1 & $2.2 \%$ \\
2 & 6 & $1.7 \%$ & 2 & $4.3 \%$ \\
3 & 21 & $5.9 \%$ & 19 & $41.3 \%$ \\
4 & 95 & $26.7 \%$ & 14 & $30.4 \%$ \\
5 & 229 & $64.3 \%$ & 10 & $21.7 \%$ \\
Total & 356 & & 46 & \\
\hline
\end{tabular}

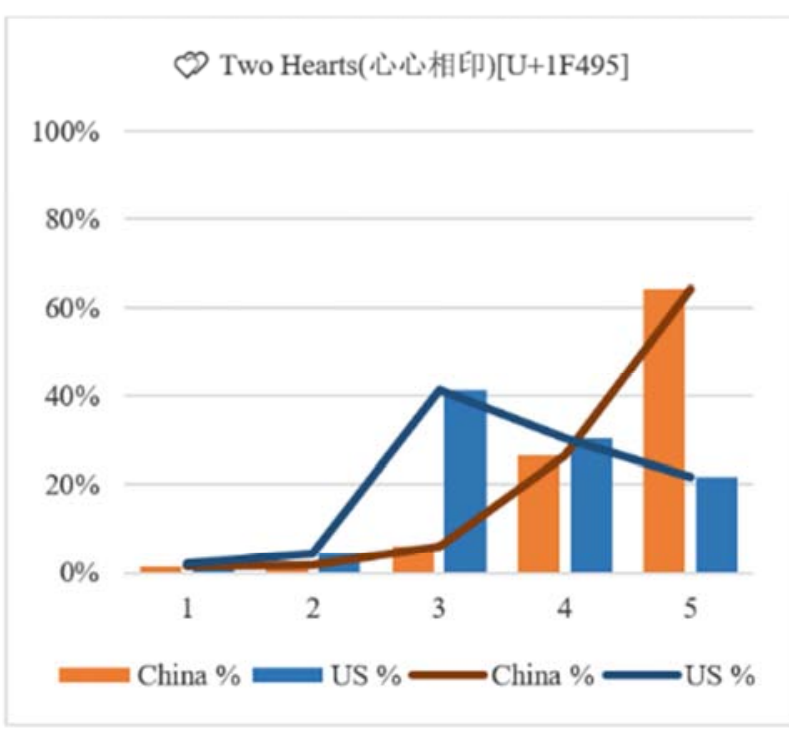

Figure 12. Histogram of the Emoji "Two Hearts".

\subsubsection{Smiling Face with Smiling Eyes}

The smiling face with smiling eyes was designed to represent joyful emotion. It shows a smiling face with eyes that are curved indicating the raising of the cheek muscles which makes the eyes appear smaller. This is part of the original Emoji 1.0 in 2015 and was approved as part of Unicode 6.0 in 2010 . The majority of U.S. users (41.3\%) rated it primarily neutral and $26.1 \%$ thought it was somewhat negative. $19.6 \%$ of the U.S. users found it somewhat positive. Chinese users felt very positive about this emoji with $37.6 \%$ finding it strongly positive and $38.5 \%$ finding it slightly positive. The weighted average of China respondents was 4.03 and U.S. was 3.20. The difference in the weighted average was 0.83. Result: Minor misalignment.

Table 15. Score Distribution of the Emoji “Smiling Face with Smiling Eyes”.

\begin{tabular}{lllll}
\hline Score & $\begin{array}{l}\text { Number of } \\
\text { Response } \\
\text { (China) }\end{array}$ & $\begin{array}{l}\text { Percentage } \\
\text { of Response } \\
\text { (China) }\end{array}$ & $\begin{array}{l}\text { Number of } \\
\text { Response } \\
\text { (U.S.) }\end{array}$ & $\begin{array}{l}\text { Percentage } \\
\text { of Response } \\
\text { (U.S.) }\end{array}$ \\
\hline 1 & 8 & $2.2 \%$ & 0 & $0 \%$ \\
2 & 22 & $6.2 \%$ & 12 & $26.1 \%$ \\
3 & 55 & $15.4 \%$ & 19 & $41.3 \%$ \\
4 & 137 & $38.5 \%$ & 9 & $19.6 \%$ \\
5 & 134 & $37.6 \%$ & 6 & $13.0 \%$ \\
Total & 356 & & 46 & \\
\hline
\end{tabular}




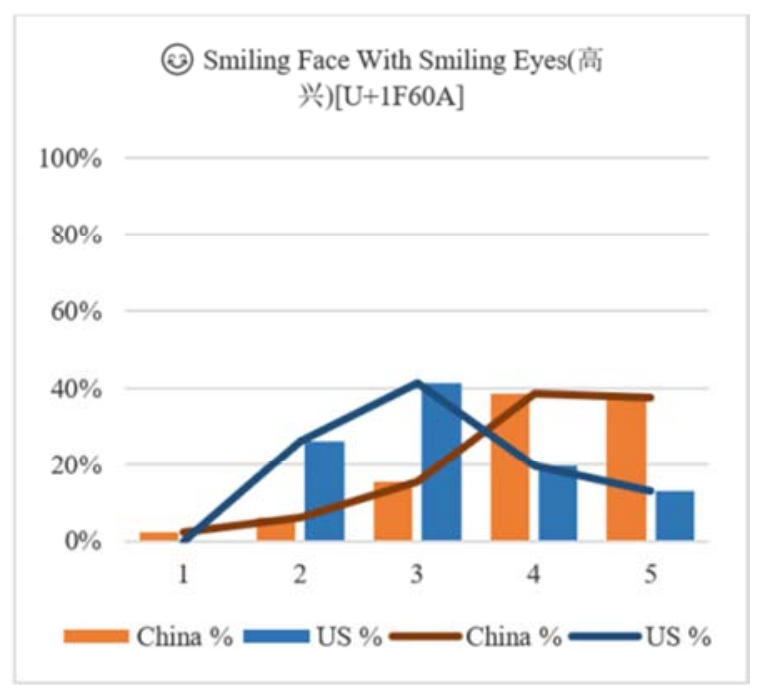

Figure 13. Histogram of the Emoji "Smiling Face with Smiling Eyes".

\subsubsection{Grinning Face with Smiling Eyes}

A face with an open smile showing upper teeth and tongue. It demotes general happiness and a comfortable relaxed face. Approved as part of Unicode 6.0 in 2010, this is part of the original emoji 1.0 in 2015. The data demonstrated the similarity of both China and U.S. users that the majority of them rated it a 3 or above 3 . A higher percentage of China users $(46.3 \%)$ considered it very positive while $15.2 \%$ of U.S. users had this conclusion, which reflected the slight difference. The weighted average of China was 4.21 and U.S. was 3.41. The D-value was 0.80 . Result: Minor misalignment.

Table 16. Score Distribution of the Emoji "Grinning Face with Smiling Eyes"

\begin{tabular}{lllll}
\hline Score & $\begin{array}{l}\text { Number of } \\
\text { Response } \\
\text { (China) }\end{array}$ & $\begin{array}{l}\text { Percentage } \\
\text { of Response } \\
\text { (China) }\end{array}$ & $\begin{array}{l}\text { Number of } \\
\text { Response } \\
\text { (U.S.) }\end{array}$ & $\begin{array}{l}\text { Percentage } \\
\text { of Response } \\
\text { (U.S.) }\end{array}$ \\
\hline 1 & 6 & $1.7 \%$ & 0 & $0 \%$ \\
2 & 10 & $2.8 \%$ & 10 & $21.7 \%$ \\
3 & 53 & $14.9 \%$ & 14 & $30.4 \%$ \\
4 & 122 & $34.3 \%$ & 15 & $32.6 \%$ \\
5 & 165 & $46.3 \%$ & 7 & $15.2 \%$ \\
Total & 356 & & 46 & \\
\hline
\end{tabular}

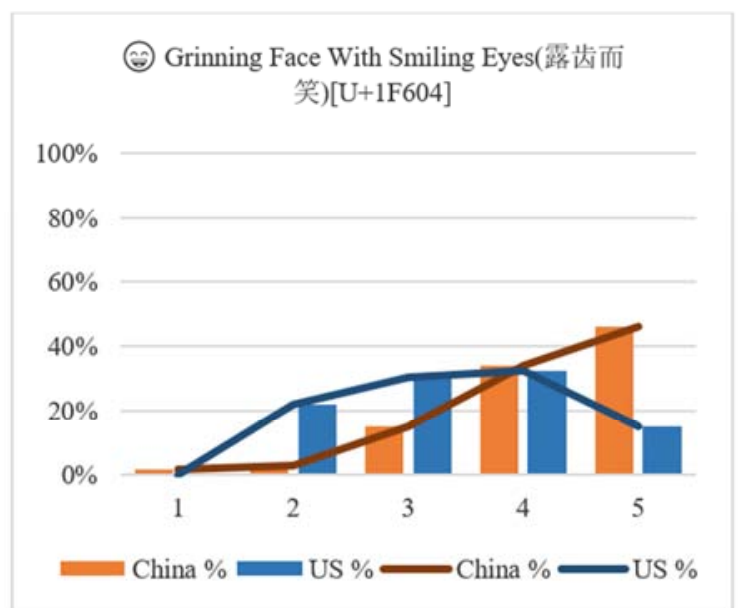

Figure 14. Histogram of the Emoji "Grinning Face with Smiling Eyes".

\subsubsection{Recycling Symbol}

The universal recycling symbol has three clockwise arrows. It is a widely recognizable symbol placed on consumer products worldwide to encourage recycling of the containers. It was part of the 3.2 version of Unicode in 2002 and added as part of Emoji 1.0 in 2015.

The majority of the responses from U.S. and China was nearly identical with this emoji. $55.9 \%$ of Chinese respondents and $54.3 \%$ of U.S. respondents agreed that it was neutral. Of the remaining respondents, China ranked more positive $34.3 \%$ versus $13 \%$ than U.S. The weighted average of U.S. respondents was 3.43 and China respondents was 2.76 which showed a slight difference between the two user groups. The D-value was 0.67. Result: Minor misalignment.

Table 17. Score Distribution of the Emoji "Recycling Symbol".

\begin{tabular}{lllll}
\hline Score & $\begin{array}{l}\text { Number of } \\
\text { Response } \\
\text { (China) }\end{array}$ & $\begin{array}{l}\text { Percentage } \\
\text { of Response } \\
\text { (China) }\end{array}$ & $\begin{array}{l}\text { Number of } \\
\text { Response } \\
\text { (U.S.) }\end{array}$ & $\begin{array}{l}\text { Percentage } \\
\text { of Response } \\
\text { (U.S.) }\end{array}$ \\
\hline 1 & 11 & $3.1 \%$ & 5 & $10.9 \%$ \\
2 & 24 & $6.7 \%$ & 10 & $21.7 \%$ \\
3 & 199 & $55.9 \%$ & 25 & $54.3 \%$ \\
4 & 45 & $12.6 \%$ & 3 & $6.5 \%$ \\
5 & 77 & $21.6 \%$ & 3 & $6.5 \%$ \\
Total & 356 & & 46 & \\
\hline
\end{tabular}

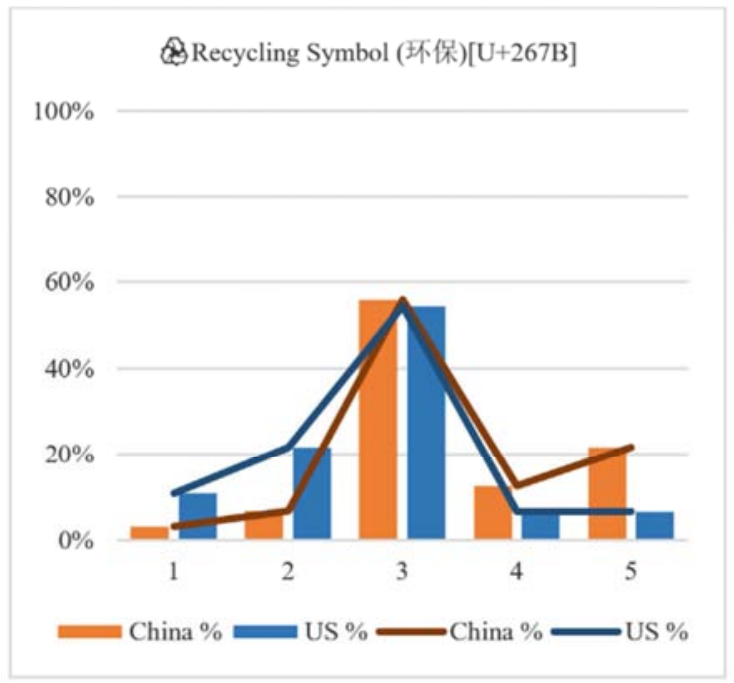

Figure 15. Histogram of the Emoji "Recycling Symbol".

\subsection{Major Misalignment}

\subsubsection{Heart Suit}

This is a variant of the Red Heart that differs primarily by the shading effect which gives it a more 2-dimensional flat appearance. The emoji was designed to represent the suit of hearts in a deck of cards and not Red Heart which symbolizes love. The data showed a strong difference between two groups of respondents. Out of 356 respondents from China, $73.9 \%$ of them rated the heart suit positive or very positive. However, only $28.3 \%$ of U.S. respondents considered it as either a positive or highly positive emoji. The majority of U.S. respondents $(52.2 \%)$ rated it on the negative side. Both user groups had a similar amount of respondents who thought the 
heart suit was a neutral symbol. The weighted average of China respondents was 4.12 while the weighted average of U.S. respondents was 2.76. Out of 15 emojis from this survey, the heart suit showed the greatest difference as the D-value was 1.36. Result: Major misalignment.

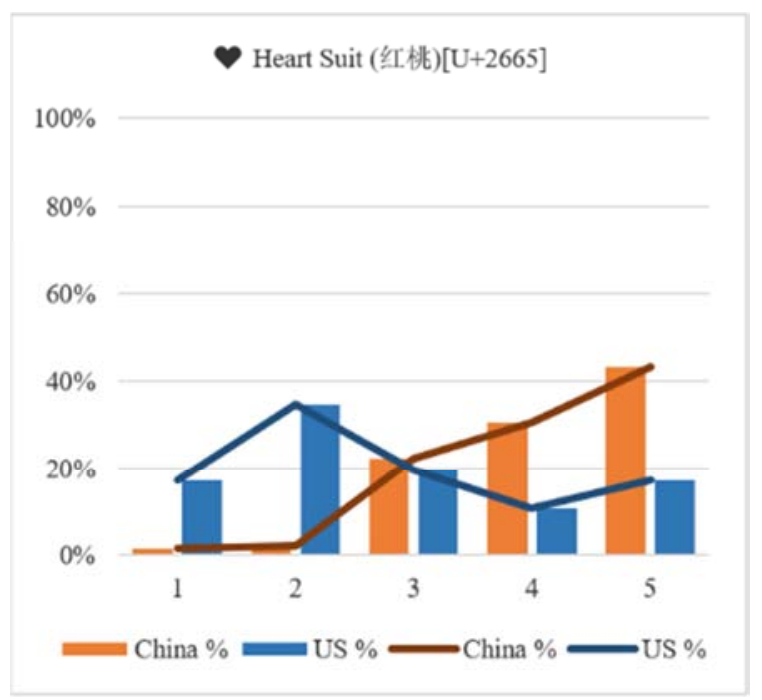

Figure 16. Histogram of the Emoji "Heart Suit".

Table 18. Score Distribution of the Emoji "Heart Suit".

\begin{tabular}{lllll}
\hline Score & $\begin{array}{l}\text { Number of } \\
\text { Response } \\
\text { (China) }\end{array}$ & $\begin{array}{l}\text { Percentage } \\
\text { of Response } \\
\text { (China) }\end{array}$ & $\begin{array}{l}\text { Number of } \\
\text { Response } \\
\text { (U.S.) }\end{array}$ & $\begin{array}{l}\text { Percentage } \\
\text { of Response } \\
\text { (U.S.) }\end{array}$ \\
\hline 1 & 6 & $1.7 \%$ & 8 & $17.4 \%$ \\
2 & 8 & $2.2 \%$ & 16 & $34.8 \%$ \\
3 & 79 & $22.2 \%$ & 9 & $19.6 \%$ \\
4 & 109 & $30.6 \%$ & 5 & $10.9 \%$ \\
5 & 154 & $43.3 \%$ & 8 & $17.4 \%$ \\
Total & 356 & & 46 & \\
\hline
\end{tabular}

\subsubsection{Red Heart}

The Red Heart symbol is the traditional symbol for love and it is usually given as a sign of affection. All designs of this symbol will emphasize the more 3-dimensional aspect of the heart to separate it from the Heart Suit emoji which is nearly identical. This was approved as part of Unicode 1.1 in 1993 and added to Emoji 1.0 in 2015. Chinese users were extremely positive with 278 out of 356 rating it a 5 of 5 representing $78.1 \%$ of the survey. U.S. users were more neutral to slightly positive as the most common selection was 3 out of 5 at $41.3 \%$. The weighted average of Chinese users was 4.67 while the weighted average of U.S. users was 3.65 leading to the $2^{\text {nd }}$ greatest separation of 1.02. Result: Major misalignment.

Table 19. Score Distribution of the Emoji "Red Heart".

\begin{tabular}{lllll}
\hline Score & $\begin{array}{l}\text { Number of } \\
\text { Response } \\
\text { (China) }\end{array}$ & $\begin{array}{l}\text { Percentage } \\
\text { of Response } \\
\text { (China) }\end{array}$ & $\begin{array}{l}\text { Number of } \\
\text { Response } \\
\text { (U.S.) }\end{array}$ & $\begin{array}{l}\text { Percentage } \\
\text { of Response } \\
\text { (U.S.) }\end{array}$ \\
\hline 1 & 5 & $1.4 \%$ & 0 & $0 \%$ \\
2 & 3 & $0.8 \%$ & 4 & $8.7 \%$ \\
3 & 18 & $5.1 \%$ & 19 & $41.3 \%$ \\
\hline
\end{tabular}

\begin{tabular}{lllll}
\hline Score & $\begin{array}{l}\text { Number of } \\
\text { Response } \\
\text { (China) }\end{array}$ & $\begin{array}{l}\text { Percentage } \\
\text { of Response } \\
\text { (China) }\end{array}$ & $\begin{array}{l}\text { Number of } \\
\text { Response } \\
\text { (U.S.) }\end{array}$ & $\begin{array}{l}\text { Percentage } \\
\text { of Response } \\
\text { (U.S.) }\end{array}$ \\
\hline 4 & 52 & $14.6 \%$ & 12 & $26.1 \%$ \\
5 & 278 & $78.1 \%$ & 11 & $23.9 \%$ \\
Total & 356 & & 46 & \\
\hline
\end{tabular}

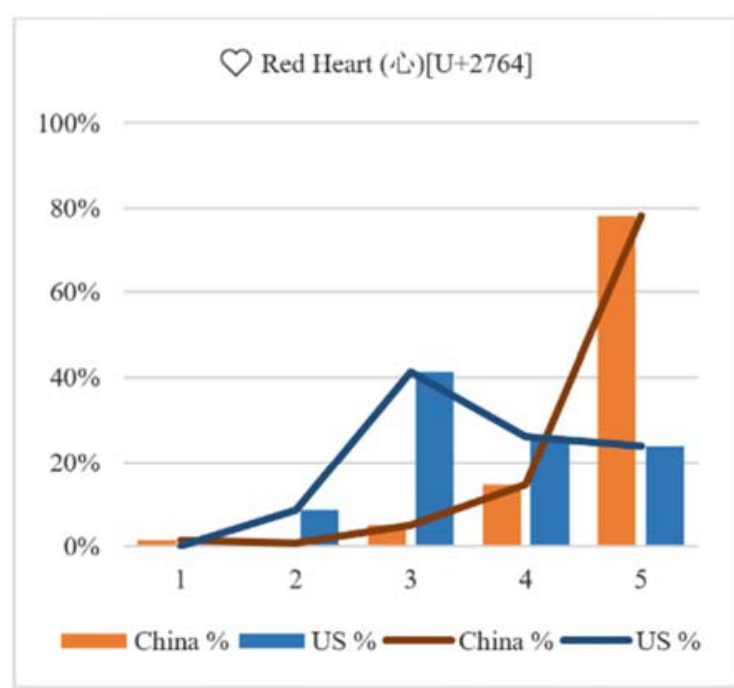

Figure 17. Histogram of the Emoji "Red Heart".

\section{Discussion}

Emojis are being used in communications every day. However, this study found that what sentiment that the users intended to send with an emoji is not always being received to the degree that it was intended. Of the 15 most commonly used emoji, only $40 \%$ (6 of 15) were found in agreement. Nearly half, $47 \%$ ( 7 of 15), varied slightly in agreement sentiment felt while $13 \%$ ( 2 of 15 ) had major misalignment with the sentiment felt.

The OK emoji, which does not have cultural differences in meaning in U.S. and China was interpreted very accurately. The loudly crying face 2 , pensive face - , weary face $\Theta$, and the unamused face $\Theta$ were all rated low by both countries' users and showed very little variance, 0.03 to 0.35 . This could be due to the evolutionary advantage of early humans reading these emotions correctly. Negative emotions were usually a pre-cursor to conflict and those who were more sensitive to negative emotions would react earlier and be able to de-escalate conflict which should lead to a survival advantage. Misinterpreting a positive facial expression would probably not cause as strong a penalty in nature than a negative one. The Smiling Face with Heart-Eyes -2 was also aligned by the two user groups.

The Heart Suit and Red Heart was the most misaligned of all the 15 emoji tested. The Heart Suit only had a very slight $2 \mathrm{D}$ versus 3D lighting difference on the Apple version of the icon and may be easily mistaken with a regular heart. A Heart Suit would denote card game and may raise thoughts of gambling which could lower its acceptance. For example, someone sending a Red Heart may mean they love you but someone sending a Heart suit may just be asking for players to join in a game of cards. 
Table 20. Score and D-value Distribution of the 15 Emojis Tested.

\begin{tabular}{|c|c|c|c|c|}
\hline Emoji & Weighted Average Score of China & Weighted Average Score of U.S. & D-value & Survey Results \\
\hline$\checkmark$ Heart Suit & 4.12 & 2.76 & 1.36 & Major misalignment \\
\hline - Red Heart & 4.67 & 3.65 & 1.02 & Major misalignment \\
\hline (;) Smiling Face & 3.79 & 2.85 & 0.94 & Minor misalignment \\
\hline (-) Face with Tears of Joy & 3.75 & 2.89 & 0.86 & Minor misalignment \\
\hline (2) Face Throwing a Kiss & 4.53 & 3.67 & 0.86 & Minor misalignment \\
\hline$\checkmark$ Two Hearts & 4.51 & 3.65 & 0.86 & Minor misalignment \\
\hline (-) Smiling Face with Smiling Eyes & 4.03 & 3.20 & 0.83 & Minor misalignment \\
\hline ()) Grinning Face with Smiling Eyes & 4.21 & 3.41 & 0.80 & Minor misalignment \\
\hline Recycling Symbol & 3.43 & 2.76 & 0.67 & Minor misalignment \\
\hline (-) Smiling Face with Heart-Eyes & 4.40 & 3.91 & 0.49 & Alignment \\
\hline$\ominus$ Unamused Face & 2.24 & 1.89 & 0.35 & Alignment \\
\hline :) Weary Face & 1.72 & 2.02 & 0.30 & Alignment \\
\hline OK Hand Sign & 3.46 & 3.20 & 0.26 & Alignment \\
\hline -) Pensive Face & 1.86 & 2.07 & 0.21 & Alignment \\
\hline Loudly Crying Face & 2.08 & 2.04 & 0.04 & Alignment \\
\hline
\end{tabular}

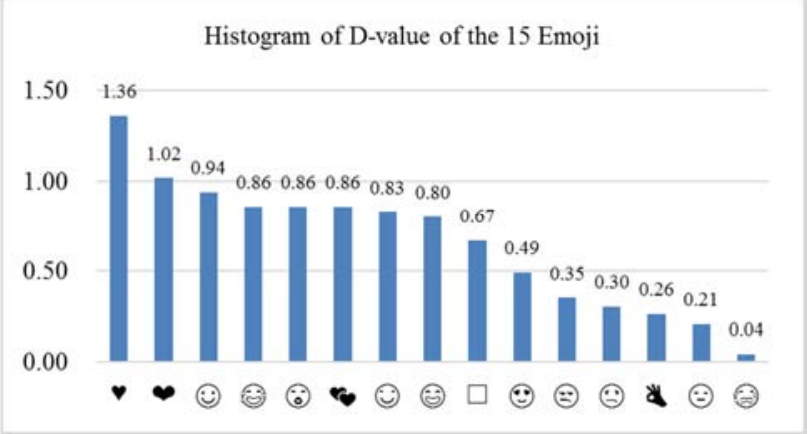

Figure 18. Histogram of the D-value of the 15Emoji.

\section{Future Work and Limitation}

Although this study has looked at some sentiment differences between U.S. and China users, it has not gone deeper to gather data on the possible reasons for divergence. In follow-up work, it is possible to supplement the study by conducting focus group interviews in an effort to gain insights into why the respondents gave their ratings.

As each platforms' emojis slightly differ, it would also warrant further study to see if the results of this study are repeatable on the other 17 other non-apple platforms with their own variants of the emoji library.

\section{Conclusion}

Emojis have been accepted by society as an alternative to text language for convenience or as compliment to online communication. However, because the emoji are just authorized for use but not governed on how they are used, netizens have interpreted their use independently and freely. This study, between two sample groups from U.S. and China, found significant differences in interpretation in 9 of the top 15 most commonly used emoji.

\section{Acknowledgements}

Thanks for the advice and help from the faculty of Guangdong University of Foreign Studies.

\section{References}

[1] Alshenqeeti, H. (2016). Are emojis creating a new or old visual language for new generations? A socio-semiotic study. Advanced in Language and Literary Studies 7: 56-69.

[2] Antheunis, M. L., Valkenburg, P. M., and Peter, J. (2010). Getting acquainted through social network sites: Testing a model of online uncertainty reduction and social attraction. Computers in Human Behavior 26: 100-109.

[3] Beltrone, G. Everyone is an emoji in this bizarre and terrifying French McDonald's ad. 11 August 2015. 10 Jan 2020. www.adweek.com/adfreak/everyone-emoji-bizarre-and-terrify ing-french mcdonalds-ad-166335.

[4] Cramer, H., de Juan, P., and Tetreault, J. "Sender-intended functions of emojis in US messaging." The 18th International Conference on Human Computer Interaction with Mobile Devices and Services. 2016, pp. 504-509.

[5] Darics, E. "Instant Messaging in work-based virtual teams: the analysis of non-verbal communication used for the contextualisation of transactional and relational communicative goals" unpublished.

[6] Eid, M., and Diener, E. (2009). Norms for experiencing emotions in different cultures: Inter-and intranational differences. Journal of Personality and Social Psychology 81: 869-885.

[7] Ganster, T., Eimler, S. C., and Krämer, N. C. (2012). Same same but different!? The differential influence of smilies and emoticons on person perception. Cyber Psychology. Behavior and Social Networking 15: 226-230.

[8] Gibson, W., Pingping, H. and Qianyun, Y. (2018). Emoji and communicative action: the semiotics, sequence and gestural actions of 'face covering hand. Discourse Context Media 26.

[9] Grabowski, P. Could a smiley make you buy? How using emoji in marketing affects conversions [AdEspresso's Experiment] 23 March 2016. 12 Jan 2020. https://adespresso.com/academy/blog/emoji-marketing-affects -conversions.

[10] Gülşen, T. T. "You Tell Me in Emojis." Computational and Cognitive Approaches to Narratology. Ed. Ogata, T., Akimoto, T. New York: IGI Global, 2016, pp. 356-378. 
[11] Haberstroh, S. (2010). College counselors' use of informal language online: Student perceptions of expertness, trustworthiness, and attractiveness. Cyberpsychology, Behavior and Social Networking 13 (4): 455-459.

[12] Hancock, J. T., Landrigan, C., and Silver, C., "Expressing emotion in text-based communication." Conference on Human Factors in Computer Systems. San Jose: ACM Press, 2007, pp. 929-932.

[13] Herring, S. C. and Ashley, D. "Nice picture comment! Graphicons in Facebook Comment Threads," the $50^{\text {th }}$ Hawaii International Conference on System Sciences. Hawaii. 2017, pp. 2185-2194.

[14] Kang, L., C. H. Tan., and J. L. Zhao. "The impact of intra-transaction communication on customer purchase behavior in E-commerce context." H. Deng, and C. Standing, Eds. Melbourne: RMIT University, 2013, pp. 1-12.

[15] Li, X. S., Chan, K. W. A., and Kim, S. (2019). Service with emoticons: How customers interpret employee use of emoticons in online service encounters. Journal of Consumer Research 45: 973-987.

[16] Miller, H., J. Thebault-Spieker, S. Chang, I. Johnson, L. Terveen, and B. Hecht. "Blissfully happy or ready to fight: Varying interpretations of emoji.'ICWSM, 2016, pp. 259-268.
[17] Novak, P. K., Smailović, J., Sluban, B., and Mozetič, I. (2015). Sentiment of emojis. PLOS ONE, 10: 1-22.

[18] Park, J., Vladimir, B., Clay, F., and Meeyoung, C. "Emoticon Style: Interpreting Differences in Emoticons Across Cultures." ICWSM '13, 2013.

[19] Tsai, J. L., Knutson, B., and Fung, H. H. (2006). Cultural variation in affect valuation. Journal of personality and social psychology 90: 288-307.

[20] Vidal, L., Ares, G., Machín, L., and Jaeger, S. R. (2015). Using Twitter data for food-related consumer research: A case study on "what people say when tweeting about different eating situations". Food Quality and Preference, 45: 58-69.

[21] Walther, J. B. and K, P. D'Addario. (2001). The impacts of emoticons on message interpretation in computer-mediated communication. Social Science Computer Review 19: 324-347.

[22] Zhu, Y., Guntuku, S. C., Lin, W., Ghinea, G., and Redi, J. A. (2018). Measuring individual video qoe: A survey, and proposal for future directions using social media. ACM Transactions on Multimedia Computing, Communications, and Applications 14: 1-24. 